\title{
Construction of an efficient development mode for buried-hill fractured reservoirs in Bohai Bay
}

\author{
Lizhen $\mathrm{Ge}^{\circledR *}$, Kaijun Tong, Zhiqiang Meng, Zhiqiang Zhu, Xiaolin Zhu \\ Tianjin Branch of CNOOC Limited, Tianjin 300452, P. R. China
}

Keywords:

Buried-hill fractured reservoirs

water-flooding system

Bohai Bay

waterflood mode

well pattern

Cited as:

Ge, L., Tong, K., Meng, Z., Zhu, Z., Zhu,

$X$. Construction of an efficient

development mode for buried-hill

fractured reservoirs in Bohai Bay.

Advances in Geo-Energy Research, 2020,

4(2): $162-172$,

doi: 10.26804/ager.2020.02.05.

\begin{abstract}
:
Fractured reservoirs are very complicated due to the coexistence of matrix and fractures. In addition, there are plenty of micro-fractures and a few dissolution pores rather than the traditional pores in the matrix of buried-hill fractured reservoirs. Thus, the performance of water flooding is mainly decided by the storage, percolation, and oil displacement characteristics of both fracture and matrix. However, the distribution and transmissibility of both macro-fractures and micro-fractures are actually heterogeneous due to the special origins. Moreover, the mass transfer between matrix and fracture is complicated. Therefore, it is very difficult to construct an effective development mode to obtain a favorable development effect. With the objective of effectively developing such reservoirs, JZ25$1 \mathrm{~S}$ in Bohai Bay in China was taken as an example in this paper. First, experiments were conducted to study the stress sensitivity of both matrix and fractures in buried-hill fractured reservoir, and simulations were performed to optimize the initial development project of depletion. Then, 3D large-scale experiments and simulations were demonstrated to study the oil displacement mechanisms and contributions of matrix and fracture for choosing optimal water flooding mode. Subsequently, the impacts of well pattern, injectionproduction ratio, and water flooding modes on development effects were studied by experiments and production practices in water flooding stage. Ultimately, an effective development mode was presented and used in the JZ25-1S reservoir.
\end{abstract}

\section{Introduction}

Naturally fractured reservoirs (NFRs) play an important role in petroleum industry in the world (Yu et al., 2009; Salimi and Bruining, 2010; Chahardowli et al., 2013). In comparison with the conventional reservoirs, NFRs consist of two systems: Fracture and matrix systems (Rangel-German and Kovscek, 2002). Generally, fracture system represents the chief paths for fluid flow and the matrix system represents the major storage volume of the reservoir fluids, and that the flow of fluids in fractured porous media is controlled by the interaction between the matrix and the fracture systems (Pooladi-Darvish and Firoozabadi, 2000). The fracture system is extremely complex and consisted of micro-and macro-fractures, the permeability of which may range from 50 to $20000 \mathrm{mD}$. In contrast, the permeability of matrix is generally lower than $10 \mathrm{mD}$ (Mason and Morrow, 2014). In addition, the matrix system may consist of many dissolution pores, which reinforce the heterogeneity of NFRs (Tong et al., 2012; Zou et al., 2013). The buried- hill fractured account for an amount of oil reserves, such as Dongshengpu and Xinggu Oilfileds. The most common method of oil recovery from buried-hill is water flooding and cyclic water flooding was used to enhanced oil recovery as well. The dual porosity model was often used to simulate the fluid flow in buried-hill fractured reservoirs. JZ25-1S is a buried-hill fractured reservoir located in Bohai Bay, which has very low apparent permeability and matrix porosity, with approximate values of $0.5 \mathrm{mD}$ and $2 \%-9 \%$, respectively. The macro-fracture density and aperture vary across the JZ25-1S reservoir. And the reserve ratio between fracture and matrix system is around 1:2 to $1: 3$. All the above features make it more difficult to be developed than conventional fractured reservoirs (Liu et al., 2009; Chen and Guo, 2011; Amin et al., 2015; Wang et al., 2018).

Water flooding is one of the most common methods to improve oil recovery from NFRs, especially when the aquifer of the reservoirs is relatively weak. However, water flooding

${ }^{*}$ Corresponding author.

E-mail address: gelzh2@cnooc.com.cn (L. Ge); tongkaijun714@126.com (K. Tong); Mengzhq@cnooc.com.cn (Z. Meng);

393241217@qq.com (Z.Zhu); Zhux14@cnooc.com.cn (X. Zhu). 2207-9963 (c) The Author(s) 2020.

Received March 23, 2020; revised April 10, 2020; accepted April 10, 2020; available online April 16, 2020. 


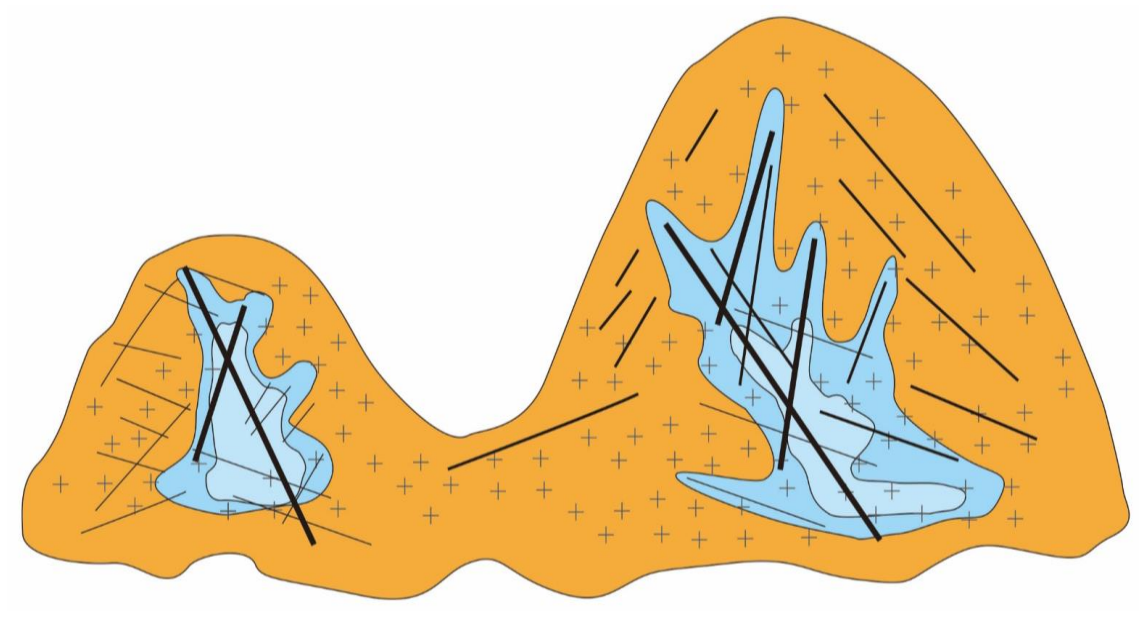

Fig. 1. Geologic structure and fracture distribution in JZ25-1S resrvoir.

are often very inefficient due to heterogeneity of the fracture and matrix system (Li et al., 2015; Harimi et al., 2019). High permeability contrast between the fracture and matrix could lead to that water mainly flow through the fractures and much of oil is trapped in the matrix system (Eliana and Norbert, 2003). Generally, capillarity and gravity can be the most important contributors to oil recovery from matrix system. When fractures are filled with water, oil in matrix system could be displaced by spontaneous imbibition if the matrix block is water-wetted (Cai et al., 2014; Yang et al., 2018; Meng et al., 2019). Under the action of capillary forces, it allows the recovery of oil from the interior of the matrix block that cannot be reached by the externally applied gradients of water flooding (Abraham, 1978). Oil recovery from matrix system depends on the many parameters, including block size, permeability, wettability, boundary conditions (Morrow and Mason, 2001; Meng et al., 2017; Wang et al., 2017; Gao et al., 2018). Understanding the fraction of oil recovery from fracture and matrix makes a contribution to designing and optimizing the water-flooding projects.

The permeability of fracture is highly dependent on the effective stress. Following the fluid recovered from the reservoirs, pressure in fracture decreases, which leads to increasing effective stress. The aperture of fracture can reduce due to increasing effective stress, which could result in permeability loss of fracture (Abass et al., 2007; Lang et al., 2014). The permeability loss due to the decreasing pore pressure is called stress sensitivity. This stress sensitivity is most pronounced in naturally fractured reservoirs where the apertures of natural fractures are very sensitive to applied closure stress resulted from reservoir depletion. Permeability loss due to increasing effective stress as a result of reservoir depletion can result in substantial cumulative recovery loss (Min et al., 2004; Tian, 2004). Generally, if the permeability of fracture is too high, water will flow through fracture system quickly, which results in the low recovery from matrix system. In contrast, if the permeability of fracture is too small, the productivity of well will decline seriously, which results in the low rate of oil recovery from NFRs (Raghavan and Chin, 2002).
Thus, In order to improve the oil recovery, it is necessary to correctly deal with the contradiction between water injection pressure keeping and water production rise and to improve the proportion of oil recovery from the matrix system.

In this paper, according to the complexity of the fractures distribution and the difference of water injection effectiveness, both experiments and simulations were carried out to study the stress sensitivity and pressure level in depletion stage. Then, 3D large-scale experiments were used to study the oil displacement mechanism and the contribution of fracture and matrix in NFRs. Moreover, both simulations and field practices were used to study water flooding modes, injection-production parameters, and well patterns for buried-hill fractured reservoirs. Finally, an efficient development mode was proposed and applied into JZ25-1S Oilfield, which will provide precious guidance to other reservoirs with similar features.

\section{Characteristics of buried-hill fractured reservoirs}

JZ25-1S is a typical buried-hill reservoirs in Archean with a burial depth of 1600 to $1880 \mathrm{~m}$. The reservoir is mainly metamorphic rock with the mainly granite of gneiss, which belongs to the buried-hill fracture reservoir of metamorphic rock. Only semi-weathered crust was developed for the longterm weather denudation, as shown in Fig. 1. The fractures were very developed and filled with weathering products in the upper part of the semi-weathered crust with strong heterogeneity. The fractures in the bottom part of the semiweathered crust are open with good connectivity, but the density is obviously lower than that of the upper part. The total porosity is about $6.8 \%$, with the porosity of $1.08 \%$ and $5.72 \%$ for fractures and matrix, respectively. The permeability ranges from 97 to $927 \mathrm{mD}$ for fractures by logging, and that of matrix is about $1 \mathrm{mD}$ by experimental tests. The main reservoir spaces are fractures and the dissolved pores distributed along the fractures, and the micro-fractures were very developed in matrix. The fracture system generally presents a network structure, and high-angle fractures is dominant. 


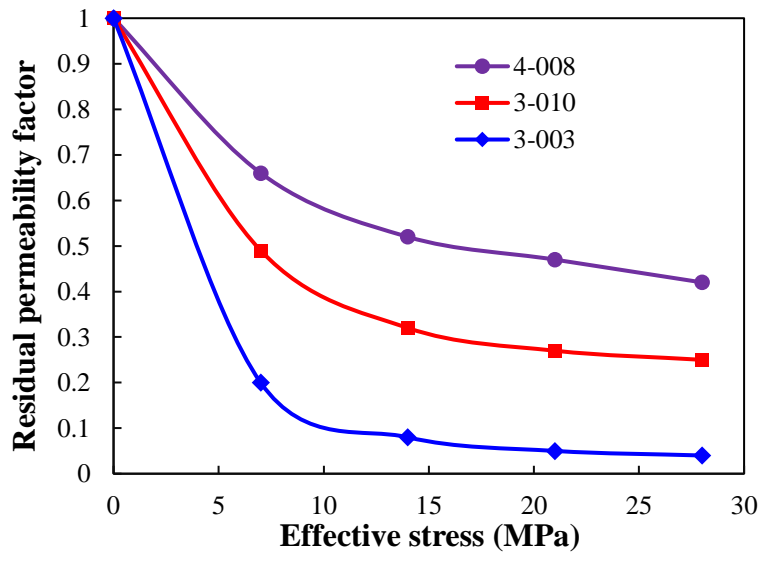

(a) Permeability residual factor VS. Effective stress for fracture

Fig. 2. Stress sensitivity of fracture and matrix.

\section{Investigations on the development mode in buried-hill fractured reservoirs}

\subsection{Depletion stage}

The natural energy of bottom water is very weak in JZ251S Oilfield. Therefore, water flooding is necessary after the initial depletion drive. Fractures are the main flow channels in such reservoir. The fracture conductivity will continuously decrease by sustained depletion due to the strong stress sensitivity of fractures, which is usually unfavorable to the subsequent production. Lots of field practices show that the production capacity gradually decreases for stress sensitivity, so the reservoir pressure should not be maintained at a low pressure. But if the pressure level is too high, the fractures are easy to water breakthrough to shorten the water-free oil production period and result in water sealing of matrix blocks. Therefore, it requires a suitable pressure to maintain oil production (Bai and Tang, 1997; Tong et al., 2015; PietraszsekMattner et al., 2017). In this part, we first studied the stress sensitivity of both fracture and matrix by experiments and production data. Then, simulations were performed to optimize the pressure maintenance level for depletion.

\subsubsection{Stress sensitivity of fracture and matrix}

Fractures and the matrix have a strong fluid-solid coupling effect for JZ25-1S Oilfield. Stress sensitivity experiments of both fractures and matrix were performed using the cores from wells \#5 and \#7. The variations of residual permeability factors with the effective stress for fracture and matrix are shown in Fig. 2(a) and Fig. 2(b), respectively. It was clear that when the effective stress increased to $12 \mathrm{MPa}$, the fracture permeability sharply decreased to $10 \%-40 \%$ of the initial value, and that of the matrix decreased to $75 \%-85 \%$ of the initial value. Since fractures may be the main flow channels for fluids, the stress sensitivity may have significant effect on oil production from fractured reservoirs. If the bottom hole pressure is too high, oil production may be low due to the small pressure gradient. However, if the bottom hole pressure is too low, oil production

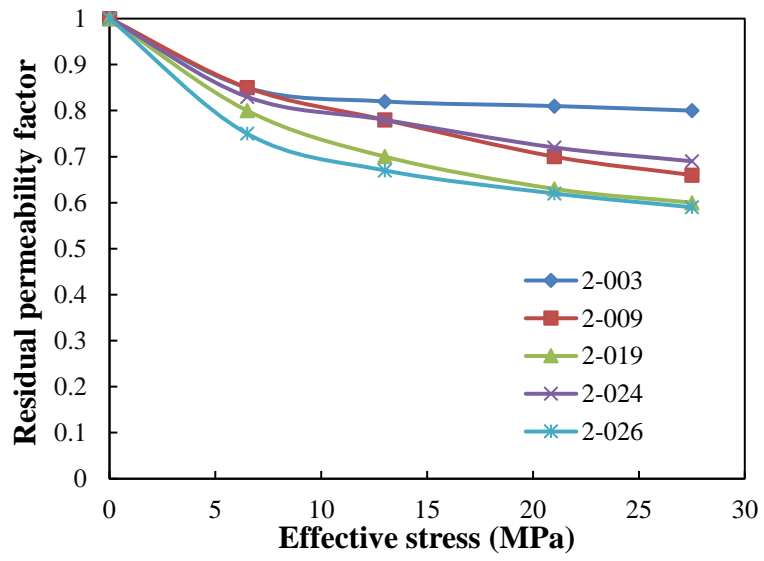

(b) Permeability residual factor VS. Effective stress for matrix

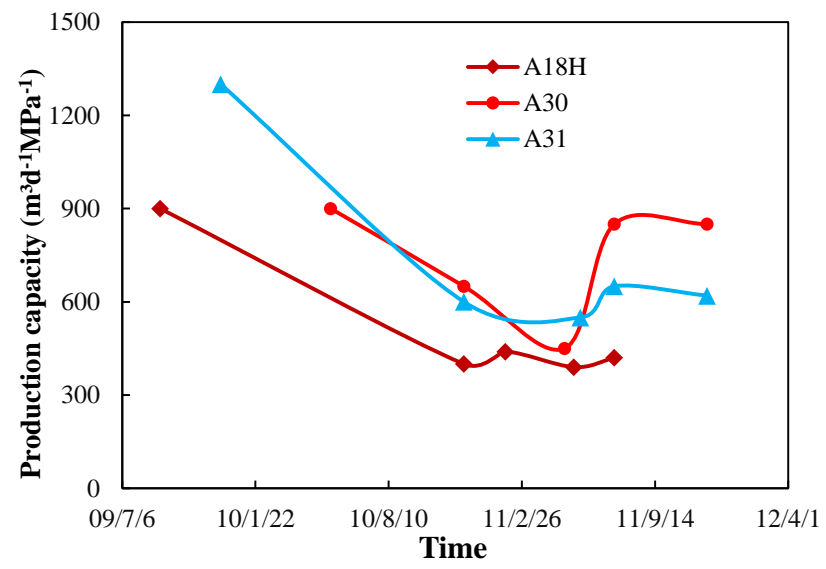

Fig. 3. Production capacity variation during production.

may be low as well due to the stress sensitivity of the fractures. The stress sensitivity can be clearly found from production data. Fig. 3 shows the production capacity of wells A18H, A30 and A31. We can see that the production capacity of these wells gradually reduces with the decrease of bottom hole pressure, which indicates the permeability decreases during production. After a period of production, the capacity of well A30 resumed in some extent as the bottom hole pressure increases, but wells $\mathrm{A} 31$ and $\mathrm{A} 18 \mathrm{H}$ resumed a little. What means that the stress deformation on the fractured reservoir caused by pressure drop is irreversible. Therefore, the pressure maintenance level should be kept at a certain level, otherwise, the stress sensitivity of fracture and matrix will seriously affect the production capacity.

\subsubsection{Optimal pressure level for depletion drive}

It is a key question to solve the contradiction between pressure maintenance level and the fast-rising of water-cut in buried-hill fractured reservoirs. According to lots of researches, the optimal pressure level should maintain from $65 \%$ to $85 \%$ of the initial reservoir pressure (Liu et al., 2009; Chen 

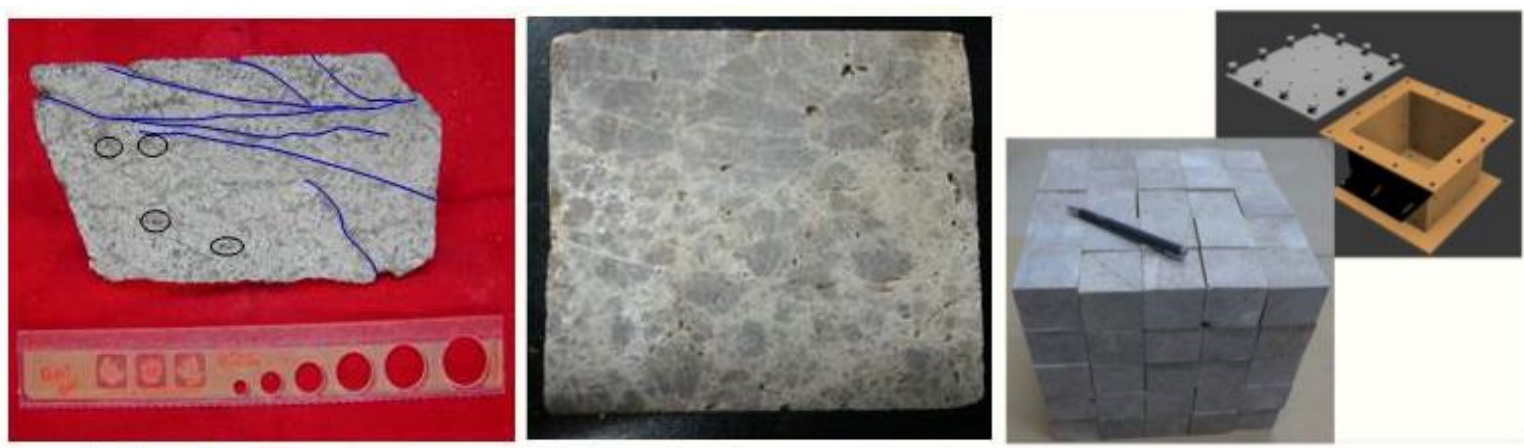

Fig. 4. The core samples used in the experiments.

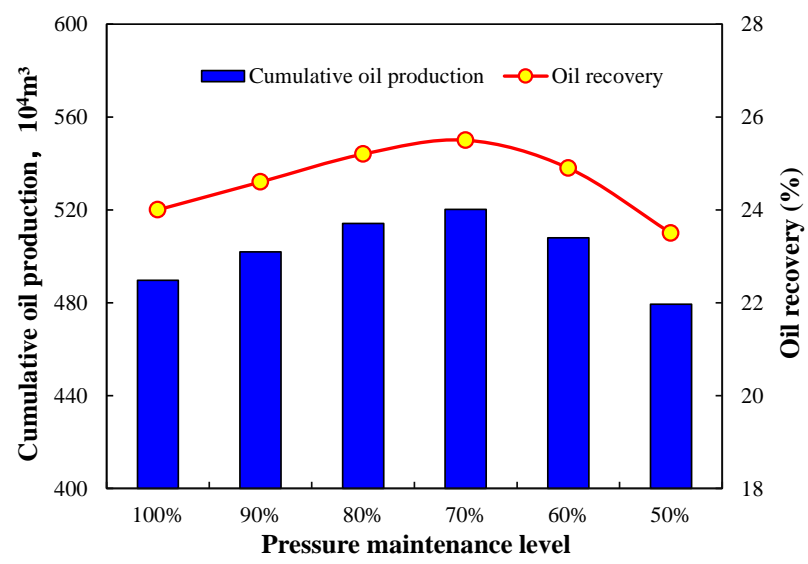

Fig. 5. Variations of oil recovery with reservoir pressure level.

et al., 2011). Based on the above stress sensitivity results, numerical models of a dual-porosity reservoir considering fracture deformation and spontaneous imbibition were established, and the pressure level to maintain was studied. Ultimately, the optimal reservoir pressure should be maintained $70 \%$ of the initial reservoir pressure by comparing the oil recovery in Fig. 4. Thus, at the depletion stage, initial depressurization and later maintenance should be applied.

\subsection{Water-flooding stage}

More than $70 \%$ of the crude oil reserves are stored in the matrix of buried-hill fractured reservoirs. It is of great importance to displace out the oil from the matrix for such fractured reservoirs. However, the matrix permeability is extremely low and the heterogeneity of micro-fractures is very strong. Therefore, it is very important to understand the displacement mechanisms and find efficient water flooding mode for achieving good effect. As the description in Section 2, the density of the fractures is higher at the top of the reservoir, and high-angle fracture is very developed. But the distribution of fractures usually depends on the production test in most cases. Therefore, the initial period of water flooding named injection test is employed to judge the fractures connectivity in the reservoir and find suitable injection-production ratio.

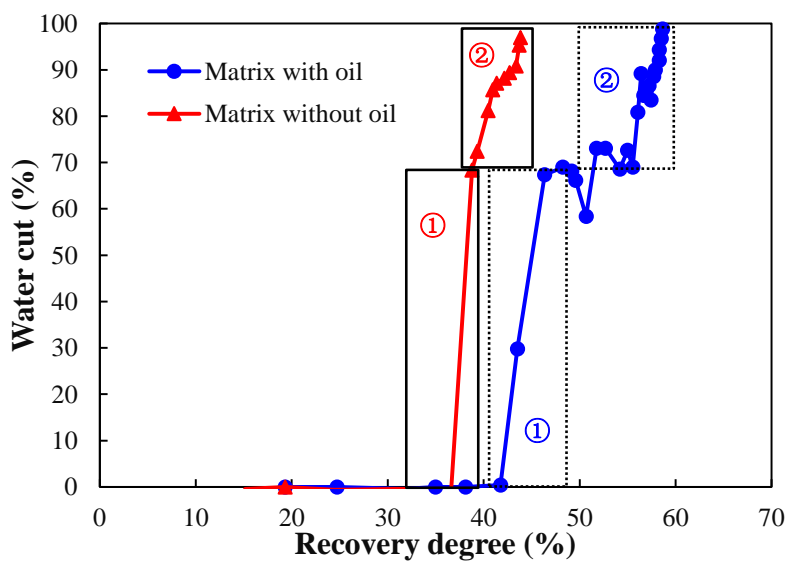

Fig. 6. Comparisons of matrix with/without saturated oil.

After that, comprehensive water injection will be conducted.

\subsubsection{Displacement mechanisms}

The production data in oilfield indicated that part of the oil could be produced from matrix. In order to directly verify this opinion, and understand the contribution of matrix, threedimensional dual-porosity models were designed in combination with mathematical model and similarity criteria (Tong et al., 2015), and water-flooding experiments were carried out. In the 3D model, the outcrop cores of metamorphic were used and there are many natural fracture in the cores (Fig. 5). The matrix in the first model was saturated with crude oil, and that was unsaturated in the second model. The viscosity of oil is $3 \mathrm{mPa} \cdot \mathrm{s}$ and density of oil is $0.9 \mathrm{~g} / \mathrm{cm}^{3}$. In the saturated matrix experiments, all cores were saturated with oil under 40 MPa for 10 hours. Then, cores were put in the model and the confining pressure with $10 \mathrm{MPa}$ were loaded. The rate of water flooding is $2 \mathrm{ml} / \mathrm{min}$. The experimental results are shown in Fig. 6, respectively. In order to clearly analyze the contribution of matrix, the recovery degree is defined as the ratio of oil output to the oil volume in fractures. The oil recovery could be divided into three stage, i.e., stage of oil production without water, stage of rapidly rising water production and stage of steady rising water production. We can see that the water-free 
recovery in the first model was $4 \%$ higher than that of the second model, which was the contribution of matrix. After water breakthrough, the water-cut increased sharply, which was the typical characteristics of fractured reservoir. For the experiments with saturated matrix, the water-cut kept around $60 \%-80 \%$ for a long time, which was the contribution of matrix as well. As a result, the ultimate oil recovery was $15 \%$ higher than that of the matrix blocks without crude oil, which meant the contribution of matrix is about $25 \%$. Moreover, about $45 \%$ of the oil in fractures and $7 \%$ of the crude oil in matrix were displaced out, respectively. Because the injected pressure was low and stable, so the contribution of matrix was mainly from spontaneous imbibition. Thus, it is significantly necessary to improve the development effect of matrix.

\subsubsection{Reservoir connectivity judgement}

Fracture heterogeneity is very strong in such reservoir, so it is necessary to confirm the connectivity before water flooding. In order to judge the fracture connectivity, injection tests were performed by pressure responding and tracer monitor in this oilfield. Fig. 7 shows the variations of pressure in different wells. It can be seen that the initial pressure in the north wells $(\mathrm{A} 17 \mathrm{H}, \mathrm{A} 18 \mathrm{H}, \mathrm{A} 25 \mathrm{H})$ is the same with the wells in the south (A30, A31, A35S). As the oil produced, the pressure decreased in all the wells. But after a long period of production, the pressures were very close in different wells. Fig. 8 shows the variation of tracer concentration in different wells. The tracers were injected from $\mathrm{A} 21 \mathrm{H}$, which is in the northern part of the oilfield. The tracer were produced from the wells A30 and A31, which located in the south of the oilfield. Which further indicated the whole reservoir has good connection. Therefore, comprehensive water injection and water injection control can be implemented.

\subsubsection{Optimal injection-production ratio}

One of the objectives of water injection is to recover the reservoir pressure. As the above investigation, the pressure should be kept above $70 \%$ of the initial pressure. In addition, a larger injection-production ratio may result in water channeling. Fig. 9 shows the production performances for different injection-production ratios. It can be seen that the watercut increases more slowly as the injection-production ratio decreases. Fig. 10 shows the variations of reservoir pressure as oil produced with different injection-production ratios. We can see that if the injection-production ratio was too low, the reservoir pressure may decrease lower than $70 \%$. Therefore, the optimal injection-production ratio should be a littler larger than unit.

Reasonably control and adjust the injection water conditions can also improve development effect. For JZ25-1S reservoirs, the northeast zone is higher than southwest zone. Oil was initially recovered from the northeast zone. More fractures were developed in the northeast location. In the southeast, as the thickness of southeast zone is thinner, oil production decreases rapidly. Under the condition of maintaining the pressure level, the key region of water flooding gradually transferred from north to south by decreasing the injection

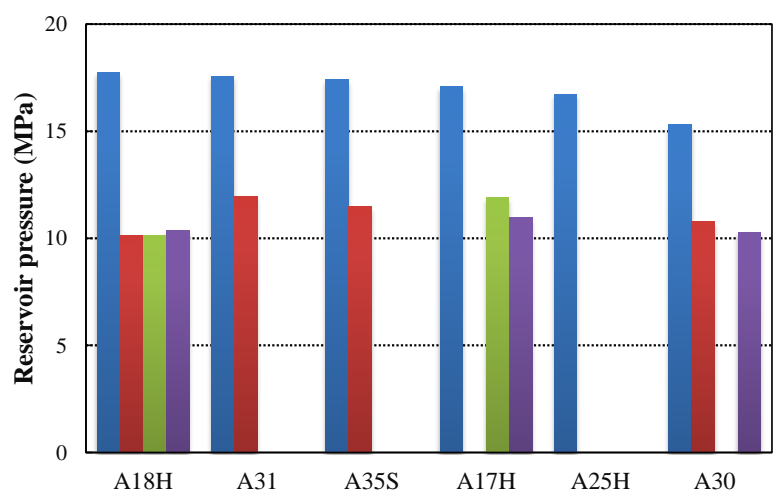

Fig. 7. The variation of pressure in different wells.

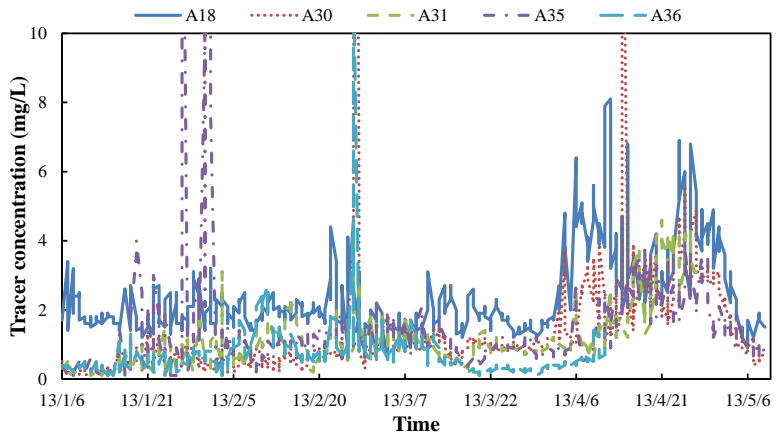

Fig. 8. The tracer concentration in different wells.

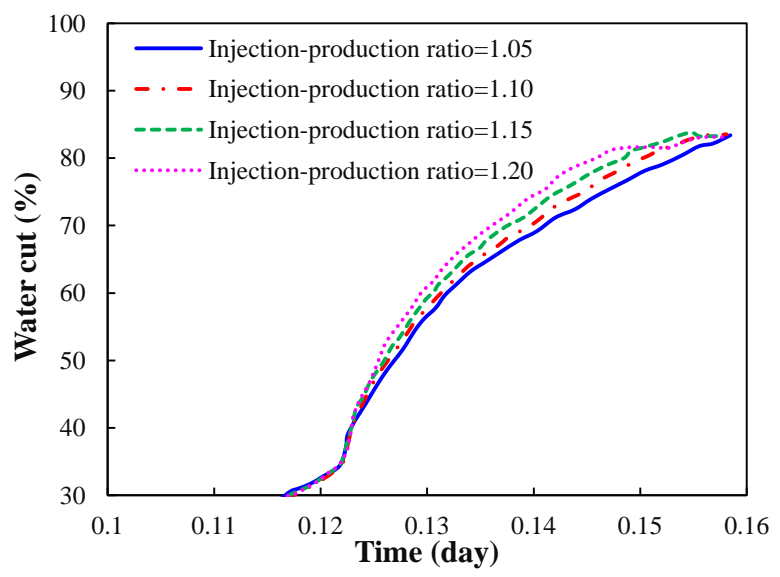

Fig. 9. The production performances for different injection-production ratios.

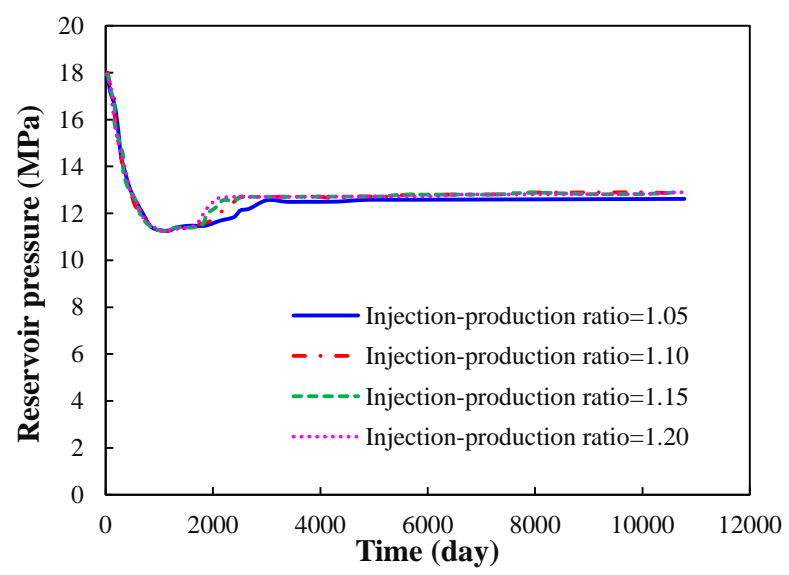

Fig. 10. The variation of reservoir pressure as oil produces for different injection-production ratios. 

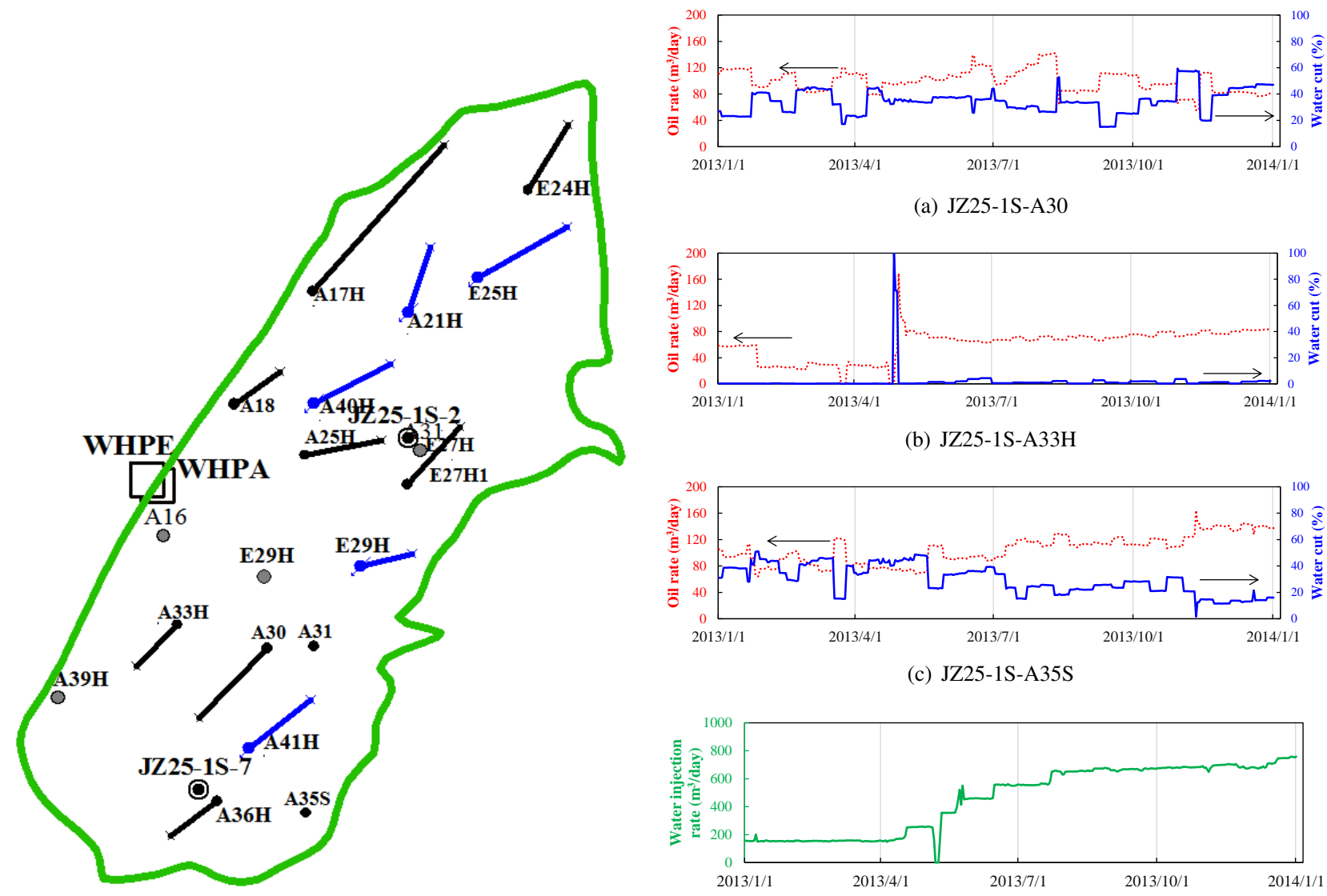

(a) JZ25-1S-A30

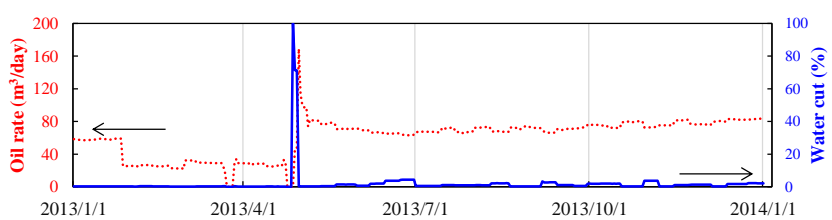

(b) JZ25-1S-A33H

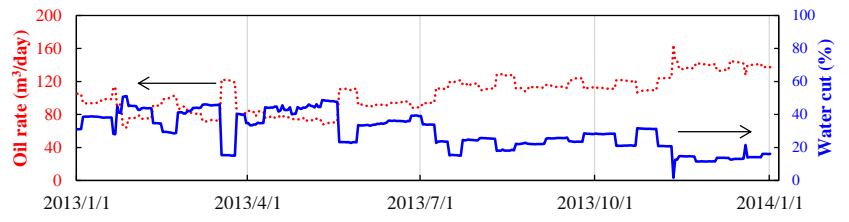

(c) JZ25-1S-A35S

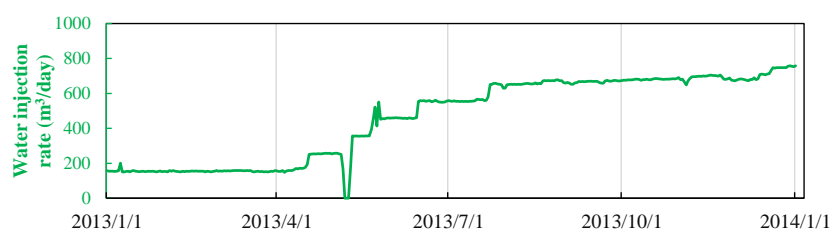

(d) JZ25-1S-A41H

Fig. 11. Comparison of the effect of water injection regulation in the north and south of buried hill.

rate of $\mathrm{A} 21 \mathrm{H}$ and increasing that of $\mathrm{A} 41 \mathrm{H}$. The oil production rates of the well group A41H are shown in Fig. 11. As the water injection rate increased, the oil production rates of this well group increased by more than $100 \mathrm{~m}^{3} /$ day.

\subsection{Comprehensive water injection stage}

With the understanding of the reservoir at the injection test stage, comprehensive water injection can be applied. In order to fully play a role of both fracture and matrix, we first performed numerical simulation to discover the source of oil at different stages. The results are shown in Fig. 12. We can see that when the water-cut was lower than $40 \%$, the fracture was the main source of oil production, but when the water-cut was higher than $20 \%$, the proportion of oil production from matrix rapidly increased. In this stage, it needed to control water breakthrough and increase the oil production by elasticity, so variable intensity of water injection should be implemented. In addition, it is necessary to control the water breakthrough from large fractures and improve flow of water in small fracture. The increasing water in the small fracture not only recover more oil from fracture system, but also improve the contacted area between matrix blocks and water, and then to enhance oil recovery from matrix system. When the water-cut was between $40 \%$ and $85 \%$, the proportions of oil production from matrix and fractures were proportionable. Oil production from matrix

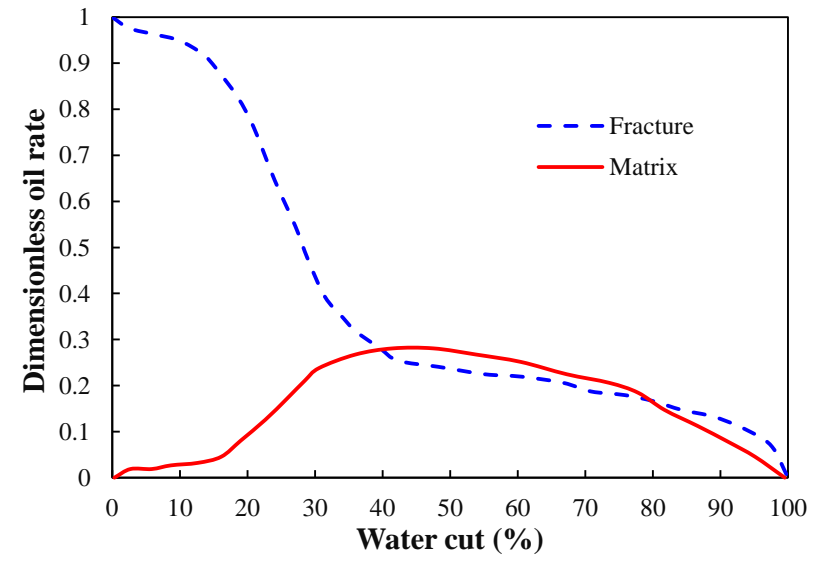

Fig. 12. The source of oil at different stages.

became the dominant action. Cyclic waterflooding should be continued to increase fluid exchange between the matrix and fractures by imbibition. When the water-cut was higher than $85 \%$, most of the matrix was sealed by water. Oil production from matrix decreased rapidly, and most of the micro-fractures were filled with water. In this stage, asynchronous water injection should be used to strength gravitational differentiation and produce more oil from relatively small fractures.

Based on the above understanding of oil production from 

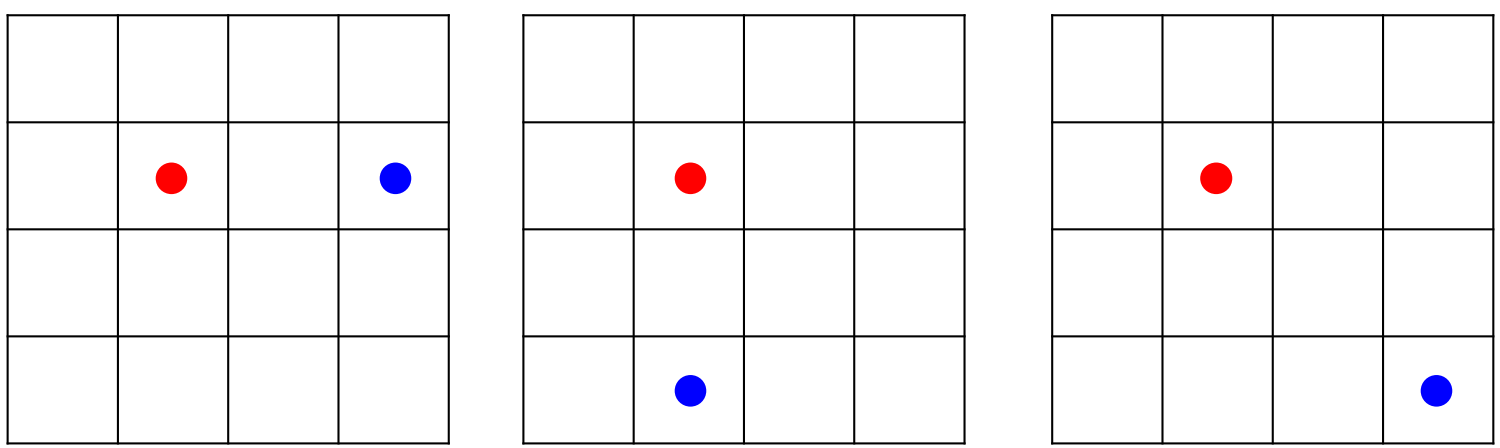

Fig. 13. Three modes of well arrangement.

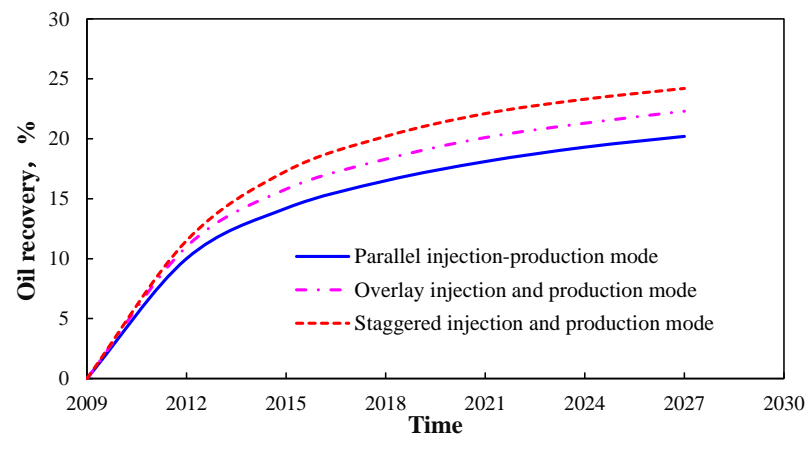

Fig. 14. Comparisons of oil recovery for different arrangement modes.

the matrix and fractures and combining the development of the similar oil field and the main contradiction in JZ25-1S Oilfield, a set of unstable water injection technology were gradually formed (Chen, 1989; Huang et al., 1995; Zhang et al., 2004), which mainly included pulse water injection at low water-cut stage, cyclic water injection at intermediate water-cut stage and asynchronous water injection at high water-cut stage. The different types of water injection were implemented in order to maintain the formation pressure, control the rise in water-cut and improve oil production from matrix.

\subsection{Three-dimensional horizontal well pattern}

Based on the distribution characteristics of fractures and energy characteristics in such reservoir, horizontal wells are usually used in this reservoir (Luo et al., 2016). In order to effectively play the role of horizontal well pattern, threedimensional quantitative geology and reservoir model were used to study the well spacing strategy in both vertical and horizontal directions. Finally, the stereoscopic development mode was put forward.

\subsubsection{Distribution of injection and production wells in vertical direction}

Because most of the fractures develop with high-angle, the oil and water wells are usually arranged based on the ancient landform. Considering the action of gravity, oil wells located on the top, and water wells on the bottom. Then, three different modes of well arrangement were presented to compare the development effect as shown in Fig. 13. In these models, water wells locate near the water-oil contact (WOC), and the elevation difference between injector and producer is larger than 40 meters. The permeability of fractures in vertical direction is larger than that in the horizontal direction. The comparisons of oil recovery for different arrangement modes are shown in Fig. 14. It is clear that the development effect of staggered injection-production is the best and that of parallel injection-production mode is the worst. The reason is that the stereoscopic mode can well play the role of gravity. In addition, the sweep efficiency for parallel model is smallest and that for the staggered mode is best. The fracture orientation may be another important factor as well. The overlay injectionproduction mode is much easier to occur water channeling for the high-angle fractures.

\subsubsection{Distribution of injection and production wells in horizontal direction}

Enlarge the sweep volume is the objective of adjusting the distribution of injection and production wells in horizontal direction. One way is to adjust the operation rules of injection wells, another way is to control the production wells of highwater in high permeable regions. Based on the above ways, more injected water will flow to the low permeable regions. Fig. 15 shows the adjustment in $\mathrm{A} 41 \mathrm{H}$ well group. Because the position of $\mathrm{A} 36 \mathrm{H}$ is relatively low, larger proportion of injected water channels into this well. The reason is that water the WOC raised during water injection, and part segment of $\mathrm{A} 36 \mathrm{H}$ is lower than WOC. Accordingly, on one hand, the water injection rate was decreased. On the other hand, the production section of $\mathrm{A} 36 \mathrm{H}$ was transferred to the top section. The production performance after adjustment shows that oil production increased from 9 to $53 \mathrm{~m}^{3} / \mathrm{d}$, and the water-cut of A35S decreased with oil production increasing as well.

\section{Pilot test and effect in JZ25-1S Oilfield}

Based on the above investigations, an efficient development mode of "initial depressurization and later maintenance for depletion and multi-staged water flooding with threedimensional horizontal well pattern of staggered injection- 


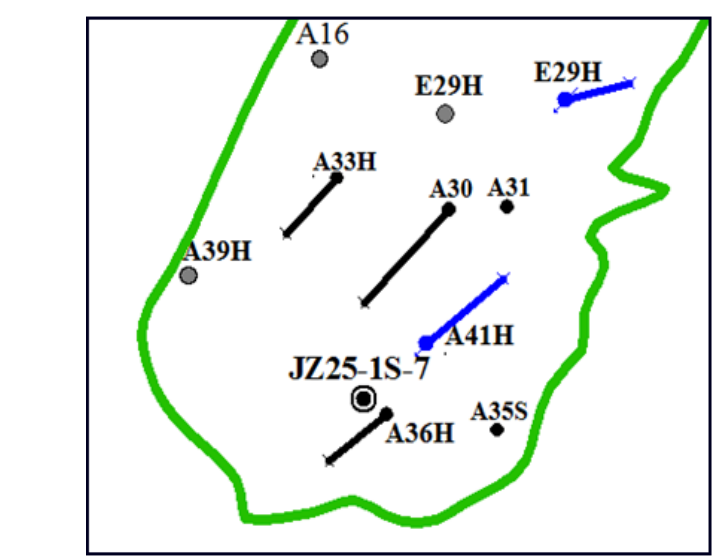

(a) Well group $\mathrm{A} 41 \mathrm{H}$
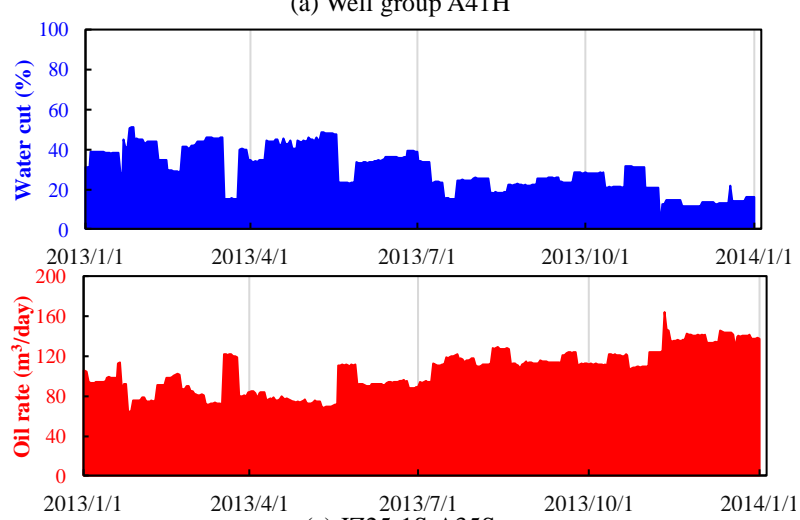

(c) JZ25-1S-A35S

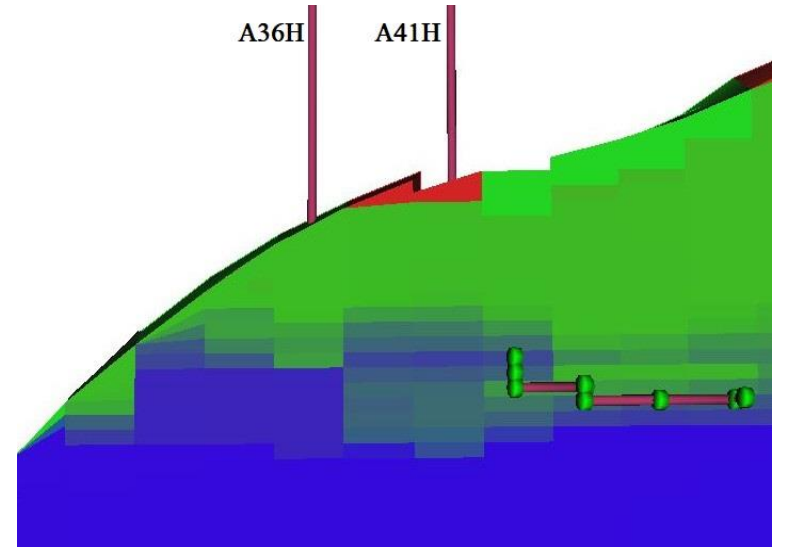

(b) Oil saturation
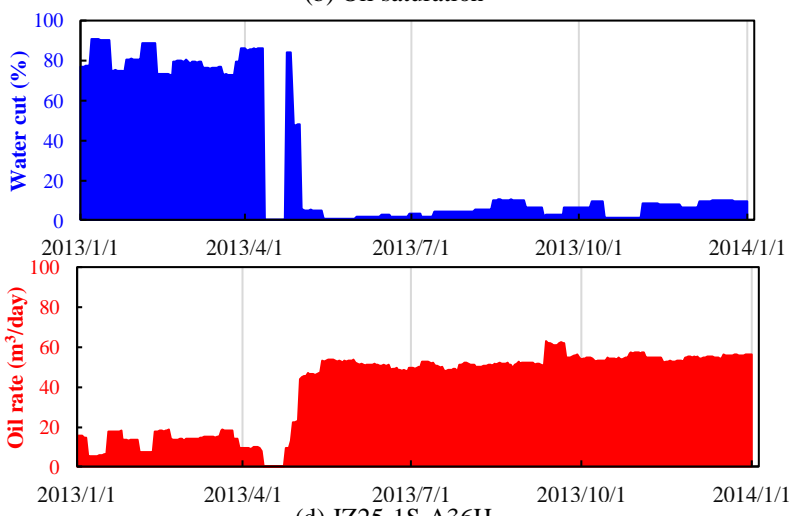

(d) JZ25-1S-A36H

Fig. 15. Effectiveness of flow direction change of injection and production well in test well groups.

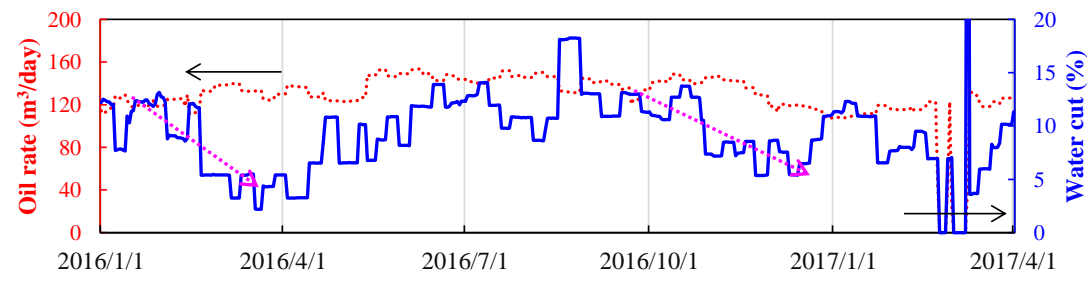

(a) JZ25-1S-A18

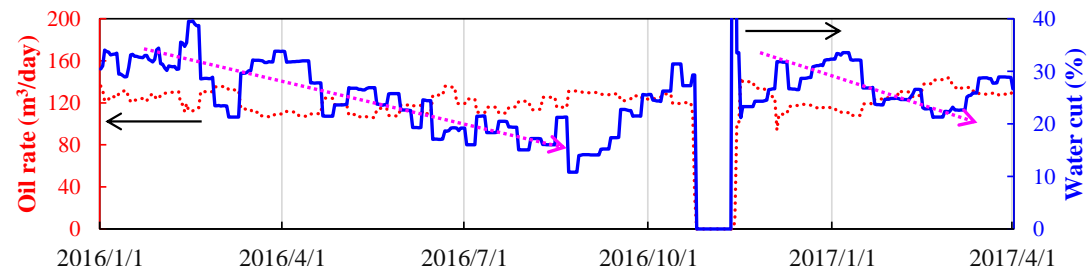

(b) JZ25-1S-A17H

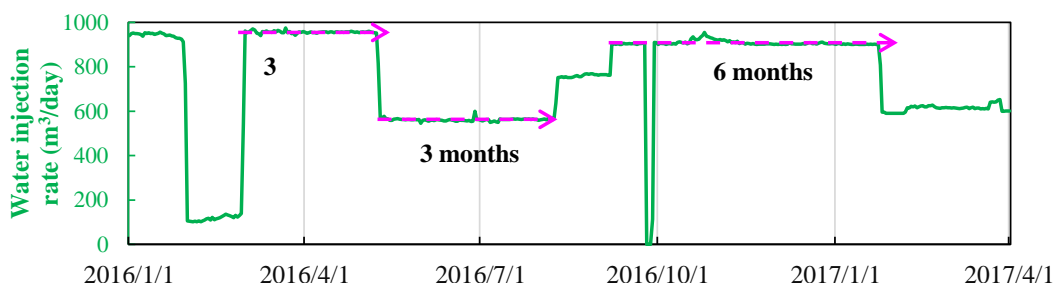

(c) JZ25-1S-A21H

Fig. 16. Pilot test and effect of the development mode in group A21H. 


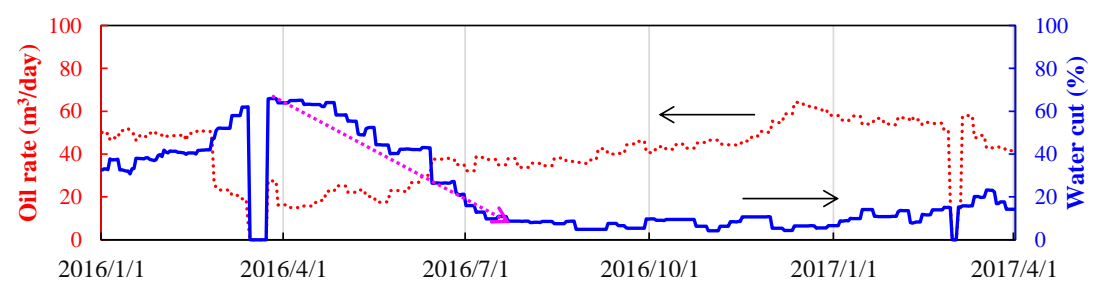

(a) JZ25-1S-A36H

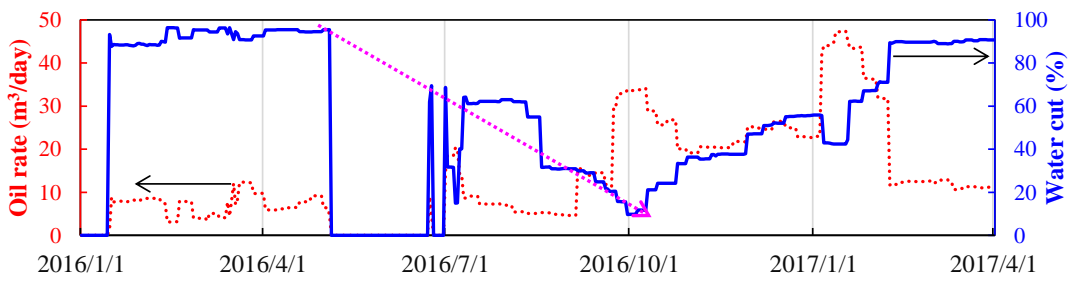

(b) JZ25-1S-A31

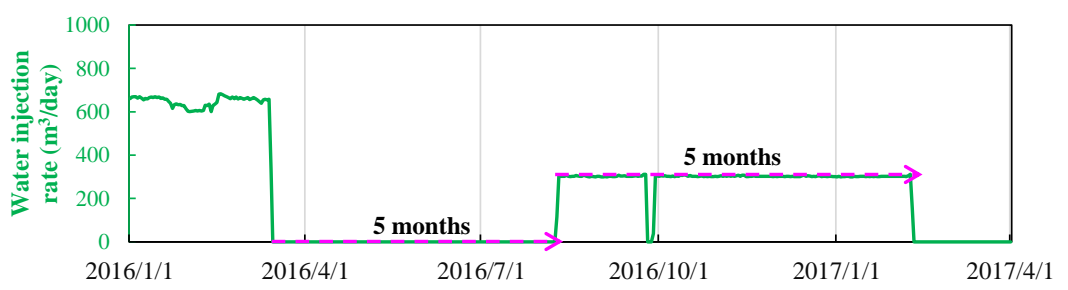

(c) JZ25-1S-A41H

Fig. 17. Pilot test and effect of the development mode in group A41H.

production" was presented. Then, it was used in the pilot of JZ25-1S Oilfield. The well groups A21H and A41H were employed, and different water injection modes were chosen based on the water-cut. In well group $\mathrm{A} 21 \mathrm{H}$, variable-intensity water flooding was used with the half-life is 3-6 months with the injection-production ratio of 0.8-1.2. The water-cut of well $\mathrm{A} 18 \mathrm{H}$ and $\mathrm{A} 17 \mathrm{H}$ decreased by $10 \%-20 \%$, and the oil production rate increased by $20 \mathrm{~m}^{3} / \mathrm{d}$ as shown in Fig. 16 . In well group $\mathrm{A} 41 \mathrm{H}$, cyclic water flooding was used with the half-life is 3-6 months with the injection-production ratio of 1.0-2.0. The water-cut of well $\mathrm{A} 31$ and $\mathrm{A} 35 \mathrm{H}$ decreased by $50 \%$, and the oil production rate increased by $30-40 \mathrm{~m}^{3} / \mathrm{d}$ as shown in Fig. 17.

\section{Conclusions}

With the objective of constructing an efficient development mode for buried-hill fractured reservoirs, all of the experiments, simulations, and oilfield practices were performed to study the oil displacement mechanisms, water flooding mode, and injection-production parameters in such reservoir, several insights have been founded:

1) The stress sensitivity of fracture system is stronger than matrix, and the optimal reservoir pressure maintenance level is about $70 \%$ of original pressure in buried-hill fractured reservoirs.

2) Although there are $70 \%$ of OOIP stored in matrix, only $7 \%$ of OOIP were displaced out by conventional water flooding. During water flooding, the contribution of matrix is around $25 \%$, and that of fractures is $75 \%$.

3) The connectivity of JZ25-1S reservoir is good, and the optimal injection-production ratio is close to unit. When the water-cut is lower than $40 \%$, oil mainly produces from fractures, and variable-intensity waterflooding should be implemented; when the water-cut is between $40 \%$ and $85 \%$, the contributions of matrix and fractures are approximate, and cyclic waterflooding should be applied; when the water-cut is higher than $85 \%$, most of the matrix was sealed by water, and asynchronous waterflooding should be used.

4) The best well arrangement mode is staggered injectionproduction mode, and parallel injection-production mode is the worst in buried-hill fractured reservoirs.

5) An efficient development mode of "initial depressurization and later maintenance for depletion, multi-staged waterflooding with three-dimensional well pattern of staggered injection-production" was presented and applied in the JZ25-1S reservoir. Good results were obtained for decreasing water-cut and increasing oil production.

\section{Acknowledgement}

This work was supported by the Major National Science and Technology Projects in China (2016ZX05058001).

\section{Conflict of interest}

The authors declare no competing interest. 
Open Access This article, published at Ausasia Science and Technology Press on behalf of the Division of Porous Flow, Hubei Province Society of Rock Mechanics and Engineering, is distributed under the terms and conditions of the Creative Commons Attribution (CC BY-NC-ND) license, which permits unrestricted use, distribution, and reproduction in any medium, provided the original work is properly cited.

\section{References}

Abass, H.H., Ortiz, I., Khan, M.R., et al. Understanding stress dependent permeability of matrix, natural fractures, and hydraulic fractures in carbonate formations. Paper SPE 110973 Presented at Saudi Arabia Section Technical Symposium, Dhahran, Saudi Arabia, 7-8 May, 2007.

Amin, D., Iman, A., Mohammad, F.N., et al. Application of the transient rate decline analysis for determining average reservoir pressure in naturally fractured reservoirs. Petroleum Explor. Dev. 2015, 42(2): 254-258.

Bai, S.Z., Tang, F. Development Model of Fractured Buried Rock Bedrock Reservoir. Beijing, China, Petroleum Industry Press, 1997. (in Chinese)

Cai, J., Perfect, E., Cheng, C.L., et al. Generalized modeling of spontaneous imbibition based on Hagen-Poiseuille flow in tortuous capillaries with variably shaped apertures. Langmuir 2014, 30(18): 5142-5151.

Chahardowli, M., Zholdybayeva, A., Farajzadeh, R., et al. Solvent-enhanced spontaneous imbibition in fractured reservoirs. Paper SPE 164908 Presented at EAGE Annual Conference \& Exhibition incorporating SPE Europec, London, UK, 10-13 June, 2013.

Chen, H., Guo, J. Improving the image of buried-hill complex structures. Abstract SEG-2011-3455 Presented at 2011 SEG Annual Meeting, San Antonio, Texas, 18-23 September, 2011.

Chen, W. The Soviet Union increased the yield by using the unstable water injection method at the later stage of some oilfields. Petroleum Explor. Dev. 1989, 12(5): 75-80.

Eliana, A., Norbert, D. Smart waterflooding tight fractured reservoirs using inflow control valves. Paper SPE 84193 Presented at SPE Annual Technical Conference and Exhibition, Denver, Colorado, 5-8 October, 2003.

Gao, L., Yang, Z., Shi, Y. Experimental study on spontaneous imbibition chatacteristics of tight rocks. Adv. Geo-Energy Res. 2018, 2(3): 292-304.

Harimi, B., Masihi, M., Mirzaei-Paiaman, A., et al. Experimental study of dynamic imbibition during water flooding of naturally fractured reservoirs. J. Pet. Sci. Eng. 2019, 174: 1-13.

Huang, Y., Shang, G., Chen, Y. Study on periodic waterflooding mechanism by nuclear magnetic resonance imaging. Geophysical Prospecting for Petroleum 1995, 16(4): 62-67. (in Chinese)

Lang, P.S., Paluszny, A., Zimmerman, R.W. Permeability tensor of three-dimensional fractured porous rock and a comparison to trace map predictions. J. Geophys. Res. Solid Earth 2014, 119(8): 6288-6307.

Li, X., Li, T., Lu, Y., et al. Petrophysical evaluation of water flooding In Bohai Bay fresh water reservoirs-A case study. Paper SPE 174395 Presented at the EUROPEC
2015, Madrid, Spain, 1-4 June, 2015.

Liu, H., Xiao, D., Li, C., et al. Optimized fractured design for buried hill reservoirs. Paper SPE 121016 Presented at Asia Pacific Oil and Gas Conference \& Exhibition, Jakarta, Indonesia, 4-6 August, 2009.

Luo, X., Li, Y., Ge, L., et al. Research and practice of efficient development technology of metamorphic buried hill fracture reservoir. China Offshore Oil and Gas 2016, 28(3): 91-96. (in Chinese)

Meng, Q., Cai, Z., Cai, J., et al. Oil recovery by spontaneous imbibition from partially water-covered matrix blocks with different boundary conditions. J. Pet. Sci. Eng. 2019, 172: 454-464.

Meng, Q., Liu, H., Wang, J. A critical review on fundamental mechanisms of spontaneous imbibition and the impact of boundary condition, fluid viscosity and wettability. Adv. Geo-Energy Res. 2017, 1(1): 1-17.

Min, K.B., Rutqvist, J., Tsang, C.F., et al. Stress-dependent permeability of fractured rock masses: A numerical study. Int. J. Rock Mech. Min. Sci. 2004, 41(7): 1191-1210.

Morrow, N.R., Mason, G. Recovery of oil by spontaneous imbibition. Curr. Opin. Colloid Interface Sci. 2001, 6(4): 321-337.

Pietraszsek-Mattner, S., Barron, J.W., Myers, R.D., et al. Predicting the impact of natural fractures on reservoir performance. Paper WPC-22-0974 Presented at 22nd World Petroleum Congress, Istanbul, Turkey, 9-13 July, 2017.

Pooladi-Darvish, M., Firoozabadi, A. Cocurrent and countercurrent imbibition in a water-wet matrix block. SPE J. 2000, 5(1): 3-11.

Raghavan, R., Chin, L.Y. Productivity changes in reservoirs with stress-dependent permeability. Paper SPE 77535 Presented at Annual Technical Conference and Exhibition, San Antonio, Texas, 29 September-2 October, 2002.

Rangel-German, E.R., Kovscek, A.R. Experimental and analytical study of multidimensional imbibition in fractured porous media. J. Pet. Sci. Eng. 2002, 36(12): 45-60.

Salimi, H., Bruining, J. The influence of wettability on oil recovery from naturally fractured oil reservoirs including non-equilibrium effects. Paper SPE 138366 Presented at SPE Latin American and Caribbean Petroleum Engineering Conference, Lima, Peru, 1-3 December, 2010.

Tian, Y. Experimental study on stress sensitivity of naturally fractured reservoirs. Paper SPE 173463 Presented at SPE Annual Technical Conference and Exhibition, Amsterdam, The Netherlands, 27-29 October, 2014.

Tong, K., Liu, H., Zhang, Y., et al. Three-dimensional physical modeling of waterflooding in metamorphic fractured reservoirs. Pet. Explor. Dev. 2015, 42(4): 589-596.

Tong, K., Zhao, C., Lv, Z., et al. Reservoir evaluation and fracture characterization of the metamorphic buried hill reservoir in Bohai Bay. Pet. Explor. Dev. 2012, 39(1): 63-69.

Wang, J., Liu, H., Xia, J., et al. Mechanism simulation of oil displacement by imbibition in fractured reservoirs. Pet. 
Explor. Dev. 2017, 44(5): 805-814.

Wang, J., Liu, H., Zhang, J., et al. Experimental investigation on water flooding and continued EOR techniques in buried-hill metamorphic fractured reservoir. J. Pet. Sci. Eng. 2018, 171: 529-541.

Yang, L., Wang, S., Cai, J., et al. Main controlling factors of fracturing fluid imbibition in shale fracture network. Capillarity 2018, 1(1): 1-10.

Yu, L., Evje, S., Kleppe, H., et al. Spontaneous imbibition of seawater into preferentially oil-wet chalk cores- experiments and simulations. J. Pet. Sci. Eng. 2009, 66(3-4): 171-179.

Zhang, J., Zhang, J., Yang, Y., et al. Mechanism and field test of increasing oil recovery in buried hill crack reservoir. Acta Petrolei Sinica 2004, 25(1): 52-56. (in Chinese)

Zou, H., Zhao, C., Yin, Z., et al. Fracture-occurring outcrop model in neoarchean crystalline rock-buried hill, Bohai Bay Basin. Natural Gas Geoscience 2013, 24(5): 879885. (in Chinese) 